\title{
1 Nitrous oxide speeds the reduction of distressing 2 intrusive memories in an experimental model of ${ }_{3}$ psychological trauma
}

\author{
4 R. K. Das ${ }^{1 *}$, A. Tamman $^{1}$, V. Nikolova ${ }^{1}$, T. P. Freeman ${ }^{1}$, J. A. Bisby ${ }^{4}$, A. I. Lazzarino ${ }^{2,3}$ and \\ 5 S. K. Kamboj ${ }^{1 *}$ \\ $6 \quad{ }^{1}$ Clinical Psychopharmacology Unit, UCL, London, UK \\ $7 \quad{ }^{2}$ London School of Hygiene \& Tropical Medicine, London, UK \\ $8{ }^{3}$ Department of Epidemiology and Public Health, UCL, London, UK \\ $9{ }^{4}$ Institute of Cognitive Neuroscience, UCL, London, UK
}

10 Background. Post-traumatic stress disorder (PTSD) involves maladaptive long-term memory formation which underlies 11 involuntary intrusive thoughts about the trauma. Preventing the development of such maladaptive memory is a key aim 12 in preventing the development of PTSD. We examined whether the $N$-methyl D-aspartate receptor (NMDAR) antagonist 13 gas nitrous oxide $\left(\mathrm{N}_{2} \mathrm{O}\right)$ could reduce the frequency of intrusive memories by inhibiting NMDAR-dependent memory 14 consolidation in a laboratory analogue of psychological trauma.

Method. Participants were randomized to inhale $\mathrm{N}_{2} \mathrm{O}(N=25)$ or medical air $(N=25)$ after viewing a negatively valenced emotional film clip ('trauma film'). Participants subsequently completed a daily diary assessing frequency of intrusive thoughts relating to the film clip. A week later, participants completed an explicit memory recall task related to the film.

Results. Post-encoding $\mathrm{N}_{2} \mathrm{O}$ sped the reduction in intrusive memory frequency, with a significant reduction by the next day in the $\mathrm{N}_{2} \mathrm{O}$ group compared to 4 days later in the air group. $\mathrm{N}_{2} \mathrm{O}$ also interacted with post-film dissociation, producing increased intrusion frequency in those who were highly dissociated at baseline. Sleep length and quality the night after viewing the film did not differ between the groups.

Conclusion. $\mathrm{N}_{2} \mathrm{O}$ speeds the reduction of intrusive analogue trauma memory in a time-dependent manner, consistent with sleep-dependent long-term consolidation disruption. Further research with this drug is warranted to determine its potential to inoculate against enduring effects of psychological trauma; however, caution is also urged in dissociated individuals where $\mathrm{N}_{2} \mathrm{O}$ may aggravate PTSD-like symptomatology.

Received 13 October 2015; Revised 6 January 2016; Accepted 20 January 2016

Key words: Intrusions, memory consolidation, nitrous oxide, PTSD.

\section{Introduction}

Post-traumatic stress disorder (PTSD) is a chronic psychiatric condition following the experience of traumatic events. Around $5 \%$ of men and $10-12 \%$ of women are estimated to experience PTSD at some point in their lives, with far higher rates (60-80\%) among rape victims (Solomon \& Davidson, 1997). The primary psychological symptoms of PTSD according to DSM-5 criteria are intrusions, avoidance, negative alterations in cognitions and mood, and alterations in arousal and reactivity (APA, 2013). Intrusions, the first of these and the hallmark of PTSD, are persistent, spontaneous, involuntary thoughts pertaining to traumatic events (Brewin, 2001b;

* Address for correspondence: Dr R. K. Das, Clinical Psychopharmacology Unit, UCL, 1-19 Torrington Place, London WC1E 7HB, UK.

(Email: ravi.das@ucl.ac.uk)
Hellawell \& Brewin, 2004). Intrusions tend to be primar- 41 ily visuospatial and somatic in nature, involving decon- 42 textualized (Michael et al. 2005), fragmentary, visual 43 re-living of aspects of the trauma (Hackmann et al. 2004). 44 Intrusions are thought to be a product of maladap- 45 tive memory (Van der Kolk et al. 1996). Elevated peri- 46 traumatic glucocorticoid (Roozendaal, 2000, 2002) and 47 noradrenaline (Roozendaal et al. 2002) levels produce 48 incomplete encoding of traumatic events which creates 49 traces lacking contextual, verbal and temporal infor- 50 mation, with strongly encoded visuospatial and auto- 51 nomic content (Brewin et al. 1996; Brewin, 2001a, b; 52 Hellawell \& Brewin, 2004). This content is subse- 53 quently consolidated into long-term traces that are re- 54 sistant to top-down voluntary recall and susceptible 55 to spontaneous, involuntary recall of decontextualized 56 visuospatial aspects of the trauma (Brewin, 2013), pro- 57 ducing the 'here and now' reliving that characterizes 58 intrusions (Ehlers et al. 2004). 
Preventing the development of such maladaptive trauma memories is therefore highly desirable in preventing the later development of PTSD symptoms in trauma victims. Previous research has examined this possibility using cognitive-behavioural procedures following analogue trauma. The performance of a visuospatially demanding task (Tetris) following the viewing of aversive video footage has been shown to reduce the reported number of intrusive memories of the footage subsequently reported by participants (Holmes et al. $2009,2010)$. While such an approach is very promising as a preventative strategy in PTSD, its practical utility is limited if victims have suffered physical injuries or are otherwise unable to engage with the task.

An alternative approach is to attempt to prevent the development of maladaptive memory traces by interfering with their consolidation. Since long-term potentiation (LTP) is thought to be the molecular basis of memory consolidation (Bliss \& Collingridge, 1993; Jones et al. 2001), interventions that inhibit LTP may prevent consolidation of traumatic memory. The 'tag-and-capture' model of LTP (Frey \& Morris, 1997) posits that two temporally dissociable forms of LTP underlie long-term consolidation of memory traces. Early LTP involves a transient (several hours) increase in co-excitability of neurons activated by learning, but does not lead to persistent ( $>24 \mathrm{~h}$ ) memory trace retention in the absence of late-phase LTP, where synaptic connections encoding the memory trace are selectively strengthened. This late-phase LTP is critically sleepdependent, with long-term memory stabilization depending upon replay of events during sleep (Stickgold, 2005; Ji \& Wilson, 2007; Rasch et al. 2007). Indeed, sleep deprivation following analogue trauma events reduces their psychological impact (Cohen et al. 2012; Porcheret et al. 2015), but may be difficult to implement clinically. As $\mathrm{N}$-methyl D-aspartate receptor (NMDAR) is critical in both phases of LTP (Sajikumar \& Frey, 2004) and memory consolidation generally (Shimizu et al. 2000), post-trauma NMDAR antagonism may prevent the consolidation of long-term maladaptive memory traces, reducing PTSD symptomatology.

Nitrous oxide $\left(\mathrm{N}_{2} \mathrm{O}\right)$ is promising in this respect, as alongside its opioid and GABAergic activity (Emmanouil \& Quock, 2007) it is antagonistic at the NMDAR (Jevtović-Todorović et al. 1998, 2001) is well tolerated, has rapid onset and offset kinetics and can be administered very easily (Amey et al. 1981). For these reasons it is currently widely used as a pre-hospital analgesic by emergency services ( $\mathrm{O}$ 'Sullivan \& Benger, 2003). It could thus be readily implemented as a potential first-line preventive treatment in the aftermath of trauma to prevent the formation of maladaptive trauma memories. However, $\mathrm{N}_{2} \mathrm{O}$ shares with other NMDAR antagonists the ability to produce profound dissociation and may interfere with the consolidation of 'protective' 115 temporal, contextual and verbal aspects of traumatic 116 experiences. Persistent dissociation during and after 117 traumatic events is a key predictor of later development 118 of PTSD (Briere et al. 2014). $\mathrm{N}_{2} \mathrm{O}$ administered after a 119 traumatic event may therefore produce paradoxical 120 worsening of PTSD symptoms through increases in dis- 121 sociation. Opportunistic studies with ketamine, a more 122 potent NMDAR antagonist and dissociative than $\mathrm{N}_{2} \mathrm{O}, 123$ have shown deleterious effects on the development of 124 PTSD following its use in an emergency setting 125 (Schönenberg et al. 2005, 2008). However, a recent ran- 126 domized control trial has shown efficacy of ketamine 127 in the treatment of chronic PTSD (Feder et al. 2014). 128 Experimental models of post-trauma $\mathrm{N}_{2} \mathrm{O}$ do not cur- 129 rently exist and are required in order to properly assess 130 its therapeutic and harmful potential. 131

In the current study, we therefore sought to examine 132 the effects of $\mathrm{N}_{2} \mathrm{O}$ on consolidation of distressing intru- 133 sive memories in a laboratory model of trauma. In line 134 with previous research using behavioural tasks 135 (Holmes et al. 2009; Holmes et al. 2010; James et al. 136 2015), we hypothesized that $50 \% \quad \mathrm{~N}_{2} \mathrm{O}$ (Entonox, 137 British Oxygen Company, UK) following an aversive 138 'trauma film' would interfere with consolidation of 139 memories of the film, evidenced by a greater reduction 140 in the frequency of self-reported intrusive thoughts 141 related to the film over the subsequent week compared 142 to inhalation of medical air. However, acknowledging 143 the potential for a deleterious effect of $\mathrm{N}_{2} \mathrm{O}$, putatively 144 due to its potent dissociative properties, we hypothe- 145 sized that its effects on intrusive memories would inter- 146 act with post-film levels of dissociation, producing less 147 benefit in those with higher dissociation levels post-film. 148

\section{Method}

\section{Participants and design}

Fifty-two participants (24 women) took part in the 151 study. Inclusion criteria were age 18-65 years, normal 152 physical health, normal or corrected to normal colour 153 vision. Exclusion criteria were self-reported historical 154 or current diagnosis of mental health issues; a history 155 of trauma, memory impairments, pregnancy or breast- 156 feeding, regular (>1 times per month) recreational use 157 of drugs other than alcohol and caffeine (including 158 $\mathrm{N}_{2} \mathrm{O}$ or other NMDAR antagonists), vitamin B12 defic- 159 iency and pneumothorax. All procedures were 160 approved by the UCL research ethics committee. 161

Stimuli and apparatus

Trauma film 163

The emotional video consisted of two clips taken from 164 the film 'Irreversible' (Studio Canal, France). The 165 
166 scenes depicted a violent rape (scene 1, $15 \mathrm{~min}$ long) 167 and a man being beaten to death in a club (scene 2, $1684 \mathrm{~min}$ long). The use of these clips was based on pilot 169 data showing a greater number of intrusions following 170 this clip than previously used multiple short scenes 171 (Soni et al. 2013).

\section{Subjective assessments}

173 To assess levels of dissociation, the Clinical 174 Administered Dissociative States Scale (CADSS; 175 Bremner et al. 1998) was used. The Beck Depression 176 Inventory (BDI; Beck et al. 1988) was used to assess 177 levels of depression, the Distress Tolerance Scale 178 (DTS; Simons \& Gaher, 2005) to assess participants' in179 dividual capacity for managing distressing experiences 180 and the Dissociative Experiences Scale (DES) as assess 181 naturalistic levels of dissociation (Carlson \& Putnam, 182 1993). Acute emotional responses to the film were 183 assessed with a set of six visual analogue scales 184 (VAS) measuring levels of disgust, fear, anger, sadness, 185 happiness and distress. These were anchored with the 186 descriptors 'not at all' and 'extremely'. A single-item 187 VAS was also used to asses drug-induced nausea. 188 After the first night of sleep following the film, partici189 pants also completed an short online survey where 190 they reported how many hours they had slept and 191 their quality of sleep compared to normal (better 192 than normal, around the same, or worse than normal).

\section{Memory assessment}

194 Participants logged intrusions in a diary via an online 195 Qualtrics interface (Qualtrics, USA). Participants 196 received daily email/smartphone prompts for 7 days 197 (starting on the day of the trauma film) to record the 198 number of intrusive memories related to the trauma 199 film they had experienced that day. The diary prompt 200 defined intrusions as 'A spontaneously occurring mem201 ory. By spontaneous we mean memories of the film that sud202 denly pop into your mind automatically. We do not mean 203 times when you deliberately think about it. The spontaneous 204 memories may pop into your mind when you are doing or 205 thinking about something completely unrelated. The main 206 thing is that you didn't mean to think about the film but 207 recalled something about it out of the blue.' Participants 208 briefly reported the content of the intrusion and the 209 number of occurrences of the intrusion that day. 210 Logged 'intrusions' that were unrelated to the film 211 were not counted.

212 A cued recall task was used to assess explicit mem213 ory of the trauma film. This consisted of ten questions 214 about occurrences in each film. Participants were 215 scored 2 for a correct answer, 1 for a partially correct 216 answer and 0 for an incorrect answer to each question.
Heart rate variability (HRV)

HRV reflects the interplay between sympathetic and 218 parasympathetic influences on the heart and indicates 219 the autonomic nervous system's response to threat 220 (Porges, 1997). Heart rate data (RR intervals) were 221 recorded using a BodyGuard 2 ECG device (FirstBeat 222 Technologies, Finland). HRV was acquired at a sam- 223 pling rate of $1000 \mathrm{~Hz}$ and expressed as the standard de- 224 viation of successive RR intervals (SDNN). A 5-min 225 epoch prior to viewing the trauma film, and a 5-min 226 epoch after the film served as pre-film (baseline) and 227 post-film indices of autonomic arousal. The recording 228 during the entire film (peri-film) along with the pre- 229 and post-film epochs were used in the statistical ana- 230 lysis of arousal effects.

\section{Drug administration}

Drug was medical $50 \% \mathrm{~N}_{2} \mathrm{O}$ in oxygen (Entonox) and 233 was administered via an Ultraflow demand valve 234 regulator (BPR Medical Ltd, UK). Participants in the 235 placebo group were fitted with an inhalation mask 236 connected a cylinder of medical air (British Oxygen 237 Company) with transparent polyethylene tubing. Gas 238 cylinders were not visible to participants in order to 239 maintain the single blind. All participants inhaled the 240 appropriate gas for $30 \mathrm{~min}$ in total.

\section{Procedure}

Day 1

After completing a telephone screening to assess eligibil- 244 ity, participants attended the study centre for the first 245 day of testing and completed informed consent and 246 the DES, DTS and BDI before being fitted with the 247 ECG device and viewing the trauma film. After this, 248 participants were fitted with inhalation masks con- 249 nected to an Entonox $\left(\mathrm{N}_{2} \mathrm{O}\right)$ or air cylinder and com- 250 pleted the baseline CADSS before gas administration 251 began. After $10 \mathrm{~min}$ of equilibration to the gas, the 252 CADSS was repeated to assess any acute changes in dis- 253 sociation. Ten minutes after cessation of gas inhalation, 254 the CADSS was completed once more. Participants were 255 finally briefed on the completion of the intrusion diary, 256 which they were required to complete on a daily basis 257 until the next testing day. Participants completed the 258 sleep survey remotely the morning after day 1 . Testing 259 commenced between 10:00 and 16:00 hours. There 260 were an equal number of participants in each group 261 who were tested in the morning and afternoon.

Participants returned to study centre and completed 264 the cued recall task at approximately the same time 265 
266 as they commenced testing on day 1. After this they 267 were debriefed and reimbursed at a rate of $£ 7.50$ per 268 hour of participation.

\section{Data handling}

Heart rate data were imported into Kubios (Tarvainen et al. 2009) for Matlab (The MathWorks Inc., USA) and artefact correction was performed using pre-defined settings. All data were analysed using $R$ ( $R$ Core Development Team, 2014) and IBM Statistical Package for the Social Sciences (SPSS) version 22 for Windows (IBM Corp, USA). For general linear models, assumptions were checked though inspection of histograms and scatterplots of standardized residuals against predicted values in models. Group differences on trait variables at baseline were assessed using independent-samples $t$ tests and $\chi^{2}$ tests.

Intrusion counts were modelled using Poisson generalized linear mixed models (GLMMs) in SPSS and the glmer function of the lme4 package (Baayen et al. 2008). Satterthwaite approximations were used to determine the degrees of freedom and robust covariance estimation to assess model effects. Model specification was based upon a priori hypotheses, with Group, Day, Gender, post-film CADSS and Group $\times$ Day and Group $\times$ CADSS terms entered as fixed effects of interest. These were selected because (1) the timecourse of intrusions was of primary interest to the study, (2) gender and dissociation predict PTSD-like symptomatology following traumatic events and (3) dissociation was hypothesized to interact with Group, due to the highly dissociative nature of $\mathrm{N}_{2} \mathrm{O}$. A random intercept per participant was specified to account for dependencies caused by repeated measurements on the same participants. For exploratory analyses on heart rate and sleep data, generalized linear models were used to model total intrusion counts, since no hypotheses were made concerning the effects of these variables on intrusions over time. Poisson models were fit using maximum likelihood estimation, with a log link function. Model fit was assessed by minimizing the finite-corrected Akaike's Information Criterion (AICc). In these models, $k>2$ main effects and interactions were assessed with sequential Bonferroni-adjusted contrasts. Outlier removal was based upon model-based residuals and influence diagnostics, as recommended by Baayen et al. (2008) and Bates (2010). These tests, alongside tests for overdispersion and fulfilment of regression assumptions, were conducted using custom scripts written in R. One extreme outlier was found and removed using these tests (a female in the $\mathrm{N}_{2} \mathrm{O}$ group) and excluded from all analyses.
Missing data

One participant's whole data (a male in the Air group) 319 was lost due to technical failure, leaving a final $N=25 \quad 320$ per group. For the cued recall $(N=4)$, HRV $(N=7) 321$ and sleep $(N=2)$ data, some data records were lost 322 due to technical failure. As the proportion of data 323 lost was small and Little's test demonstrated that the 324 data was missing completely at random $\left(\chi_{187}^{2}=177.94,325\right.$ $p=0.671)$, these data records were imputed using the 326 EM algorithm in SPSS. Analysis was conducted with 327 and without these imputations, and the results were 328 not affected in any meaningful way. Reported results 329 therefore include imputed values.

\section{Results}

Fifty participants aged between 18 and 41 years (mean \pm S.D.: $24.4 \pm 4.9$ ) contributed data to the analyses. Descriptive statistics for baseline and trait measures are given in Table 1. The groups did not differ in any of these measures at baseline. 336

\section{Acute responses to trauma film}

The ability of the trauma film to produce intense nega- 338 tive affective responses and reduction in positive affect 339 was assessed using 2 (Group) $\times 2$ (Time: pre-film/ 340 post-film) ANOVAs on each of the VAS items. 341 Inferential and descriptive statistics for these tests are 342 presented in Table 2. The film produced marked 343 increases in negative and decrease in positive affect 344 and these changes did not differ between groups. 345

\section{Primary analysis}

Drug effects on intrusive memory

Mean daily intrusion frequency over the week follow- 348 ing the trauma film were low in both groups $\left(\mathrm{N}_{2} \mathrm{O}: 349\right.$ $1.155 \pm 1.068$; Air: $1.068 \pm 0.858)$. A $t$ test on these data 350 showed no significant differences between the absolute 351 number of experienced intrusions between the $\mathrm{N}_{2} \mathrm{O} 352$ group and the Air group $\left(t_{48}=0.458, p=0.649\right) .353$ However, as previously observed in studies using the 354 trauma paradigm, intrusion frequency was highest in 355 the first few days after the video (Soni et al. 2013) 356 and declined over the course of the week (James et al. 357 2015).

For the primary mixed model analysis the AICc for 359 the full model (1261.1) was significantly lower than 360 an intercept-only comparison model (1359.73), indicat- 361 ing an improvement in overall complexity-penalized 362 model fit following the addition of the predictors 363 $\left(F_{16,36}=10.051, p<0.001\right)$. 364

Significant effects of Day $\left(F_{6,315}=16.141, p<0.001\right) 365$ and Gender (women $>$ men; $F_{1,30}=16.131, p<0.001$ ) and 366 
Table 1. Descriptive statistics for baseline subjective measures with associated tests of significance. Data represent mean \pm S.D

\begin{tabular}{|c|c|c|c|c|}
\hline & $\mathrm{N}_{2} \mathrm{O}(\mathrm{N}=25)$ & $\operatorname{Air}(N=25)$ & Test statistic & Significance \\
\hline Gender & $\mathrm{F}=14 / \mathrm{M}=11$ & $\mathrm{~F}=13 / \mathrm{M}=12$ & $\chi_{1}^{2}=0.081$ & 0.777 \\
\hline BDI score & $7.31 \pm 7.79$ & $5.42 \pm 5.27$ & $t_{48}=1.01$ & 0.324 \\
\hline DTS score & $34 \pm 9.6$ & $38.71 \pm 9.38$ & $t_{48}=1.75$ & 0.086 \\
\hline DES amnesia & $2.88 \pm 3.88$ & $2.44 \pm 4.12$ & $t_{48}=0.381$ & 0.705 \\
\hline DES derealization & $1.35 \pm 3.08$ & $2.51 \pm 4.37$ & $t_{48}=1.09$ & 0.281 \\
\hline DES absorption & $9.33 \pm 9.18$ & $9.83 \pm 8.64$ & $t_{48}=0.196$ & 0.846 \\
\hline STAI & $39.38 \pm 9.68$ & $38.33 \pm 9.77$ & $t_{48}=0.382$ & 0.704 \\
\hline CADSS baseline & $19.96 \pm 5.17$ & $18.71 \pm 4.7$ & $t_{48}=0.894$ & 0.376 \\
\hline CADSS on-gas & $45.23 \pm 20.86$ & $23.42 \pm 4.33$ & $t_{48}=5.213$ & $<0.001$ \\
\hline CADSS post-gas & $33.38 \pm 12.4$ & $22.21 \pm 4.02$ & $t_{48}=4.355$ & $<0.001$ \\
\hline
\end{tabular}

BDI, Beck Depression Inventory; DTS, Distress Tolerance Scale; DES, Dissociative Experiences Scale; STAI, State-Trait Anxiety Inventory; CADSS, Clinical Administered Dissociative States Scale.

Table 2. Acute emotional responses to trauma film. Statistics represent mean \pm S.D. F values are given below their respective effects in the $2 \times 2$ ANOVA.

\begin{tabular}{|c|c|c|c|c|c|c|c|c|c|c|}
\hline & \multicolumn{2}{|l|}{$\mathrm{N}_{2} \mathrm{O}$} & \multicolumn{2}{|l|}{ Air } & \multirow[b]{2}{*}{ Group ME } & \multirow[b]{2}{*}{ Sig. } & \multirow[b]{2}{*}{ Time ME } & \multirow[b]{2}{*}{ Sig. } & \multirow[b]{2}{*}{ Interaction } & \multirow[b]{2}{*}{ Sig. } \\
\hline & Pre-film & Post-film & Pre-film & Post-film & & & & & & \\
\hline Disgust & $0.8 \pm 4$ & $72.8 \pm 27.2$ & $0.8 \pm 2.8$ & $69.6 \pm 3.5$ & 0.226 & 0.637 & 257.3 & $<0.001$ & 0.164 & 0.688 \\
\hline Fear & $2.4 \pm 06.6$ & $29.6 \pm 25.4$ & $2.5 \pm 5.3$ & $34.69 \pm 3.3$ & 0.101 & 0.752 & 53.38 & $<0.001$ & 0.151 & 0.7 \\
\hline Anger & $1.2 \pm .3 .3$ & $51.6 \pm 3.4$ & $6.7 \pm 2.1$ & $51.7 \pm 35.7$ & 0.103 & 0.75 & 99.8 & $<0.001$ & 0.458 & 0.502 \\
\hline Sadness & $5.6 \pm 15.3$ & $46.4 \pm 35.5$ & $7.5 \pm 11.1$ & $39.2 \pm 31.3$ & 0.425 & 0.517 & 70.381 & $<0.001$ & 1.193 & 0.28 \\
\hline Happiness & $62.4 \pm 2.24$ & $19.2 \pm 2.1$ & $60 \pm 28.3$ & $25 \pm 26$ & 0.117 & 0.733 & 97.077 & $<0.001$ & 1.129 & 0.293 \\
\hline Distress & $6.8 \pm 17.7$ & $42.8 \pm 28.9$ & $5.8 \pm 15$ & $52.5 \pm 32.2$ & 0.418 & 0.521 & 99.994 & $<0.001$ & 1.242 & 0.271 \\
\hline
\end{tabular}

ME, Main effect. For all effects, degrees of freedom are 1, 48

367 critically a Group $\times$ Day $\left(F_{6,315}=2.382, p=0.029\right)$ and a

Group $\times$ Dissociation $\left(F_{1,13}=5.602, p=0.034\right)$ interaction were found. A Wald test on the variance of the intercept was highly significant (variance $=0.371, Z=$ 3.095, $p=0.002$ ).

The Day effect represented a significant reduction in intrusions from day 1 to day $2(\beta=-0.775,95 \% \mathrm{CI}$ -1.289 to $\left.-0.262, t_{315}=2.971, p=0.003\right)$ and all subsequent days (all $\beta^{\prime} s<-0.112, t^{\prime} \mathrm{s}>2.83, p<0.005$ ).

The Group ${ }^{*}$ Day interaction reflected that this reduction in intrusions between day 1 and day $2(\beta=-1.33$, $t_{315}=-2.767, p=0.007,95 \% \mathrm{CI}-2.32$ to -0.341$)$, day 1 and day $3\left(\beta=-1.655,95 \% \mathrm{CI}-2.93\right.$ to $-0.38, t_{315}=$ $-2.924, p=0.007$ ) and all subsequent days (all $\beta^{\prime} S$ $\left.<-1.89, t^{\prime} \mathrm{s}>4.35, p^{\prime} \mathrm{s}<0.0005\right)$ was significant only in the $\mathrm{N}_{2} \mathrm{O}$ group. In the Air group, there was no significant reduction in intrusions between day 1 and day 2 $\left(\beta=-0.396,95 \% \mathrm{CI}-1.451\right.$ to $0.66, t_{315}=-0.739, p=$ $0.461)$ or day $3(\beta=-0.958,95 \%$ CI -1.994 to 0.078 , $\left.t_{315}=2.082, \quad p=0.08\right)$. A significant reduction in intrusions (compared to day 1) was not observed in 387 the Air group until day $4(\beta=-1.453,95 \%$ CI -2.298388 to $\left.-0.608, t_{224}=4.331, p<0.001\right)$. The reduction in the 389 frequency of intrusions was therefore faster following 390 post-encoding $\mathrm{N}_{2} \mathrm{O}$ than air (see Fig. 1). 391

The Group $\times$ CADSS interaction represented a 392 significant positive predictive relationship between 393 post-film dissociation levels and intrusion frequency 394 in the $\mathrm{N}_{2} \mathrm{O}$ group $(\beta=0.085,95 \%$ CI $0.008-0.162,395$ $t=2.367, p=0.034)$ but not in the Air group $(\beta=-0.006,396$ $95 \%$ CI $-0.083-0.0071, t=0.198, p=0.849$ ) indicating a 397 potential baseline-dependency of the effects of 398 $\mathrm{N}_{2} \mathrm{O}$-induced dissociation on intrusion frequency (see 399 Fig. 2). $\quad 400$

Cued and free recall 401

The groups did not differ in correct recall of events in 402 scene $1\left(t_{48}=0.696, p=0.49\right)$ or scene $2\left(t_{48}=1.014, p=403\right.$ 0.316). However, correct recall was relatively low for 404 

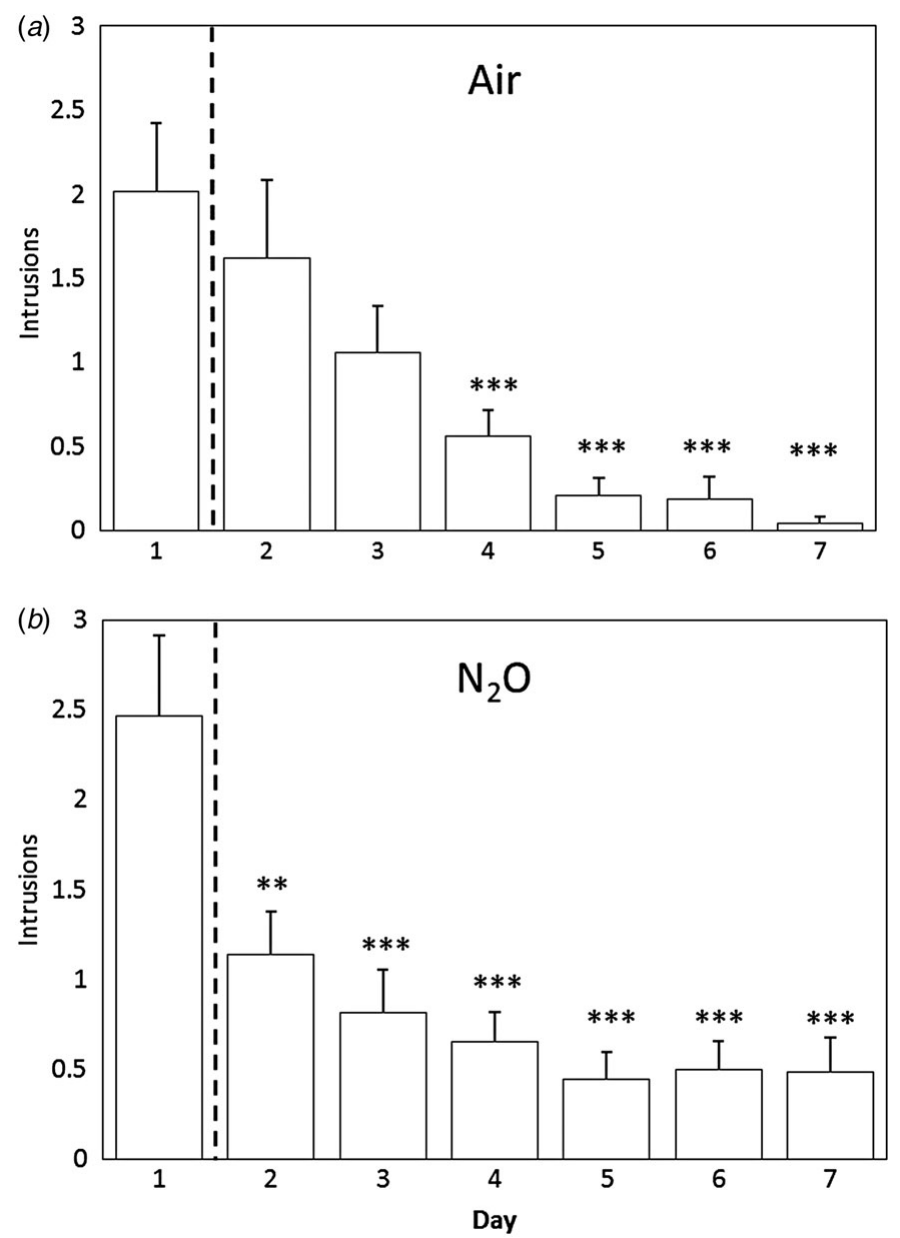

Fig. 1. Faster reduction in intrusion frequency in following post-encoding nitrous oxide $\left(\mathrm{N}_{2} \mathrm{O}\right)$. Bars represent mean + S.E.M. Denoted significance is for simple contrasts of each day against day 1 intrusion frequency. ${ }^{* *} p<0.01,{ }^{* * *} p<0.001$. The vertical dotted line indicates the first night of sleep following encoding of the trauma film.

scene $1\left(\mathrm{~N}_{2} \mathrm{O}\right.$ group: $11.36 \pm 3.4$; Air group: $\left.11.94 \pm 2.4\right)$ and lower still for scene $2\left(\mathrm{~N}_{2} \mathrm{O}\right.$ group: $8.52 \pm 4.13$; Air group: $7.52 \pm 2.7)$.

\section{Drug-induced dissociation and nausea}

A 3 (baseline, on-gas, post gas) $\times 2$ (Group) mixed ANOVA on CADSS scores found main effects of Group $\left(F_{1,48}=23.9, p<0.001, \eta_{\mathrm{p}}^{2}=0.332\right)$, Time $\left(F_{2,96}=\right.$ $\left.39.242, p<0.001, \eta_{\mathrm{p}}^{2}=0.45\right)$ and a Group $\times$ Time interaction $\left(F_{2,96}=18.37, p<0.001, \eta_{p}^{2}=0.277\right)$. The groups did not differ in dissociation at baseline $\left(F_{1,48}=0.8\right.$, $\left.p=0.376, \eta_{\mathrm{p}}^{2}=0.016\right)$, but the $\mathrm{N}_{2} \mathrm{O}$ group were significantly more dissociated than the Air group during gas administration $\left(F_{1,48}=25.212, p<0.001, \eta_{\mathrm{p}}^{2}=0.344\right)$ and $5 \mathrm{~min}$ after cessation of inhalation $\left(F_{1,48}=17.756\right.$, $\left.p<0.001, \eta_{\mathrm{p}}^{2}=0.27\right)$. These data are shown in Fig. 3. There was no effect of Group $\left(F_{1,48}=2.069, p=0.157\right.$, $\left.\eta_{\mathrm{p}}^{2}=0.041\right)$, Time $\left(F_{2,96}=1.467, p=0.237, \eta_{\mathrm{p}}^{2}=0.03\right)$ or interaction $\left(F_{2,96}=1.77, p=0.186, \eta_{\mathrm{p}}^{2}=0.036\right)$ on selfrated nausea.

\section{Exploratory analyses}

$H R V$

A 2 (Group) $\times 3$ (Time: pre-film, peri-film, post-film) 426 mixed ANOVA on SDNN data found a highly signifi- 427 cant main effect of time $\left(F_{2,96}=39.12, p<0.001, \eta_{\mathrm{p}}^{2}=428\right.$ $0.449)$, driven by an increase in SDNN post-film, com- 429 pared to peri-film $\left(t_{48}=6.702, p<0.001, r=0.7\right)$ and 430 pre-film baseline $\left(t_{48}=7.966, p<0.001, r=0.75\right)$ epochs. 431 There was no interaction between Time and Group 432 $\left(F_{2,96}=0.165, p=0.848, \eta_{\mathrm{p}}^{2}=0.003\right)$ and no main effect 433 of Group $\left(F_{1,48}=3.179, p=0.081, \eta_{\mathrm{p}}^{2}=0.062\right)$.

Sleep

As sleep is critical for memory consolidation (Gais \& 436 Born, 2004; Stickgold, 2005) and $\mathrm{N}_{2} \mathrm{O}$ may affect 437 sleep quality (Lahti et al. 2011), we examined whether 438 drug-related changes in sleep were responsible for 439 the observed drug effects on intrusion frequency. The 440 groups did not differ in the hours of sleep after 441 




Fig. 2. Differential predictive power of pre-gas dissociation on intrusion frequency between groups. Nitrous oxide $\left(\mathrm{N}_{2} \mathrm{O}\right)$ group = solid circles; Air group = clear circles; CADSS, Clinical Administered Dissociative States Scale.

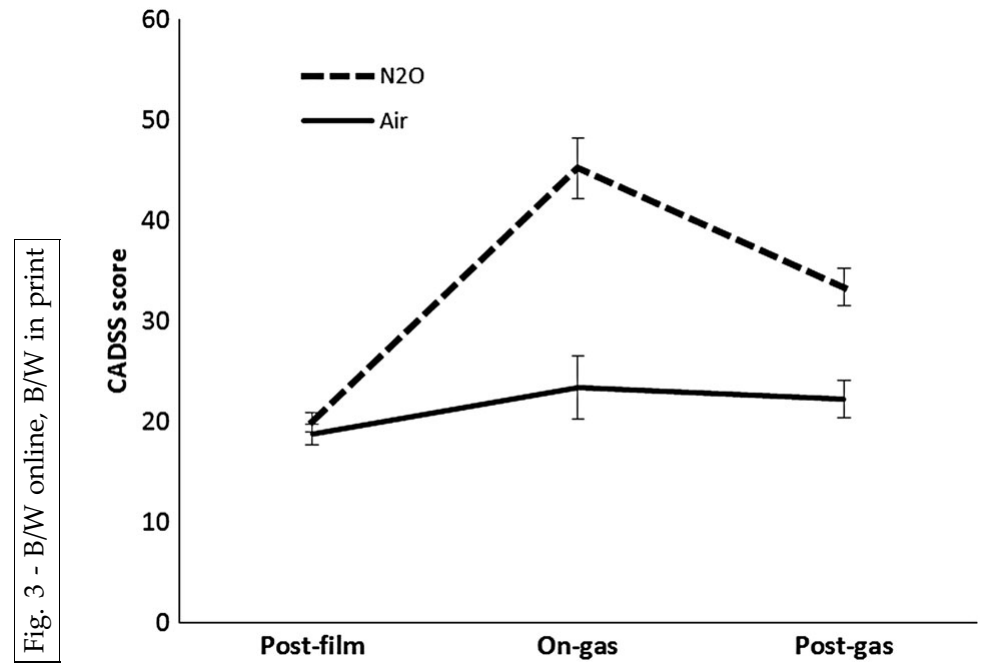

Fig. 3. Changes in dissociation following nitrous oxide $\left(\mathrm{N}_{2} \mathrm{O}\right)$ and Air. Bars represent s.E.M. CADSS, Clinical Administered Dissociative States Scale.

watching the film $\left(t_{48}=0.987, p=0.328, r=0.14\right)$. Critically, modelling total number of intrusions (sum over the week) as a function of Group, hours of sleep and their interaction found no effect of hours of sleep $(\beta=-0.071,95 \%$ CI -1.70 to $0.027, p=0.155)$ nor an interaction between Group and hours of sleep $(\beta=$ $0.007,95 \% \mathrm{CI}-0.146_{\mathrm{r}}$ to $\left.0.161, p=0.924\right)$. A $\chi^{2}$ test on rated sleep quality (better than normal, the same as normal, worse than normal) found no group differ- 450 ences in proportions of participants experiencing 451 enhanced or disturbed sleep $\left(\chi_{2}^{2}=0.487, p=0.923\right)$. 452

Drug guess

A $\chi^{2}$ of Group against drug guess $\left(\mathrm{N}_{2} \mathrm{O}\right.$, placebo, don't 454 know) found that participants could generally tell 455 
456 which gas they received, owing to the strong effects of $457 \mathrm{~N}_{2} \mathrm{O}\left(\chi_{2}^{2}=33.44, p<0.001\right)$. Twenty-two participants in 458 the $\mathrm{N}_{2} \mathrm{O}$ group guessed correctly, with none guessing 459 'placebo' and three said 'don't know'. Three partici460 pants in the Air group guessed $\mathrm{N}_{2} \mathrm{O}, 19$ guessed Air 461 and 3 said 'don't know'.

\section{Discussion}

463 The current study tested whether a 30-min inhalation 464 of, $\mathrm{N}_{2} \mathrm{O}$ could reduce intrusion frequency if adminis465 tered following an experimental analogue of trauma.

466 Although the total number of intrusions experienced 467 between the $\mathrm{N}_{2} \mathrm{O}$ and Air groups did not differ signifi468 cantly, the time-course of intrusion frequency showed 469 clear differences, with the $\mathrm{N}_{2} \mathrm{O}$ group experiencing a 470 markedly faster drop-off in intrusion frequency than 471 the Air group. Intrusion frequency in the $\mathrm{N}_{2} \mathrm{O}$ group 472 showed an exponential reduction while the Air 473 group experienced a more gradual, linear reduction 474 in intrusive thoughts over the week.

475 This difference was most pronounced between day 1 476 (the day of the trauma film) and day 2 (the day after; 477 see Fig. 1). These findings are consistent with a 'tag 478 and capture' model of LTP, resulting in a sleep479 dependent consolidation-impairing effect of $\mathrm{N}_{2} \mathrm{O}$ via 480 antagonism of NMDARs. In the current study, it is un481 likely that $\mathrm{N}_{2} \mathrm{O}$-induced NMDAR antagonism had any 482 direct effect on late-phase LTP, due to the rapid offset 483 of central activity upon cessation of inhalation, but 484 may have affected late-phase consolidation via inhib485 ition of downstream plasticity-related protein synthesis 486 during early LTP (i.e. reducing the level of 'tagging' of 487 trauma-film related representations).

488 Whether this mechanism underlies the current 489 effects are unclear, as $\mathrm{N}_{2} \mathrm{O}$ is not purely selective for 490 the NMDAR and it is possible that its $\mathrm{GABA}_{\mathrm{A}}$ or opi491 oid activity may have contributed to, or even be re492 sponsible for, the observed effects (McGaugh, 2004). 493 However, mechanistic considerations are important 494 determining whether and when $\mathrm{N}_{2} \mathrm{O}$ (or indeed other 495 drugs that interfere with consolidation) may be useful 496 in reducing the development of maladaptive fear 497 memory. The primary limitation of secondary preven498 tion strategies targeting memory is that they are se499 verely time-limited. In many scenarios, it may not be 500 possible to provide medical care to victims immediate501 ly after trauma. However, interventions may be effica502 cious for several hours after traumatic events. It has 503 been shown, for example, that delayed behavioural 504 interventions can retroactively strengthen memory 505 traces via a putative late-LTP mechanism (Dunsmoor 506 et al. 2015) hours after original learning. The extent of 507 this 'window of opportunity' remains to be estab508 lished, although it is likely to be bounded on the upper end by the onset of sleep. However, recent re- 509 search into the potential of behavioural interventions 510 (James et al. 2015) and NMDAR antagonism (Das 511 et al. 2013) during memory reconsolidation following 512 retrieval and destabilization suggest that such inter- 513 ventions could be employed in a potentially non time- 514 limited manner.

Importantly, self-reported sleep length and quality 516 were not found to be affected by $\mathrm{N}_{2} \mathrm{O}$. Thus the effects 517 cannot simply be attributed to altered sleep following 518 $\mathrm{N}_{2} \mathrm{O}$. Interestingly, we found that hours of sleep fol- 519 lowing encoding did not predict intrusion frequency. 520 The measures of sleep quality employed here were ne- 521 cessarily crude, however, and there is now a body of 522 evidence suggesting that specific phases of sleep (par- 523 ticularly slow-wave) (Diekelmann \& Born, 2010) are 524 key for consolidation. We are unable to say whether 525 such specific oscillatory elements of sleep were affected 526 by $\mathrm{N}_{2} \mathrm{O}$ in the current study. Future research may 527 benefit from the use of electroencephalography to as- 528 sess the potential mechanisms of interventions that pu- 529 tatively target memory consolidation. Similarly, the 530 observed effects are unlikely to be attributable to dif- 531 ferential stress responses to the film, as HRV did not 532 differ between groups and subjective responses to the 533 film were equivalent. However, further research may 534 benefit from more direct measures of glucocorticoid 535 responses in the trauma film paradigm, given the 536 known interactions between glucocorticoids, sleep 537 and memory consolidation (Payne \& Nadel, 2004). 538

\section{Limitations}

There were no group differences in absolute intrusion 540 frequency in the current study, which could be inter- 541 preted as evidence for a lack of effect of $\mathrm{N}_{2} \mathrm{O}$ on intru- 542 sive memories. However, intrusion frequency in the 543 current study was generally low. Indeed this is quite 544 typical of the trauma film paradigm (Bisby et al. 545 2009; Holmes et al. 2009; Soni et al. 2013). The nature 546 of the data (count) and high proportion of low counts 547 can obscure potentially clinically significant effects and 548 reduce the sensitivity of simple between-group ana- 549 lyses. This highlights the fact that, although the current 550 study drew upon a well validated and replicated para- 551 digm (Bisby et al. 2009; Holmes et al. 2009; Holmes et al. 552 2010; James et al. 2015) the intrusive memory effects we 553 produced were far milder than those following true 554 traumatic events. This can produce problems with 555 regards to 'room for improvement' from baseline 556 rates. Thus while one might normally expect an attenu- 557 ation of effects when moving from an experimental 558 model in healthy volunteers to a clinical intervention, 559 the opposite may be true in the case of this paradigm, 560 
561 where baseline intrusion frequency is higher in the 562 latter.

563 In the absence of absolute group differences in num564 bers of intrusions, if the current findings are replicated 565 in a clinical sample, speeding the reduction of intru566 sion frequency could still be clinically important, as 567 shortening disease course may prevent the develop568 ment of secondary comorbid psychiatric disorders 569 such as depression and suicide, which are rife among 570 people with a diagnosis of PTSD (O'Donnell et al. 571 2004).

572 In the current study, $\mathrm{N}_{2} \mathrm{O}$ also produced pro573 nounced dissociation and higher levels of post-film 574 dissociation, prior to drug predicted more subsequent 575 intrusions in the $\mathrm{N}_{2} \mathrm{O}$ group. This is problematic for 576 a post-trauma intervention, as dissociation has been 577 associated with the development of chronic PTSD 578 (Murray et al. 2002; Halligan et al. 2003). The exact 579 mechanism by which dissociation may lead to 580 increased intrusions is unclear, but it may reduce the 581 availability of attentional and cognitive resources for 582 encoding and consolidation of temporal and context583 ual information (Van der Kolk \& Fisler, 1995; 584 Verwoerd et al. 2008) surrounding traumatic events. 585 The dissociative profile of $\mathrm{N}_{2} \mathrm{O}$ might therefore attenu586 ate the beneficial effects of weakening the consolida587 tion of trauma memory, or in extreme cases of 588 dissociation, may even produce worsening of symp589 toms. Caution is therefore required in translating the 590 current findings to the clinic, as there is scope for ag591 gravation of PTSD-like symptomatology.

592 The applicability of the current findings to indivi593 duals following real-life trauma remains to be estab594 lished, as the current study produced only a mild 595 trauma analogue in a healthy sample. Given the cur596 rent results, further research with $\mathrm{N}_{2} \mathrm{O}$ is required to 597 replicate these effects in a clinical sample and establish 598 the potential benefits and dangers of its use following 599 traumatic events. As $\mathrm{N}_{2} \mathrm{O}$ is an effective and portable 600 analgesic, it is already very widely used by emergency 601 services for pre-hospital pain management (Fisher et al. 602 2006). Given the current results, it is possible that this 603 practise has unintended (beneficial or deleterious) 604 effects on maladaptive memory formation in the post605 trauma period. Prospective studies of the development 606 of maladaptive memory following traumatic events 607 where $\mathrm{N}_{2} \mathrm{O}$ (or indeed other NMDAergic analgesics, 608 such as ketamine) has been administered as a first-line 609 analgesic will be useful in determining the extent of 610 such effects.

\section{Conclusion}

612 The current study provides the first evidence, to our 613 knowledge, that $\mathrm{N}_{2} \mathrm{O}$ may speed the reduction in intrusion frequency following encoding of stressful 614 events through consolidation-dependent mechanisms. 615 Although much further work is required to establish 616 clinical efficacy, these findings suggest that $\mathrm{N}_{2} \mathrm{O}$, or 617 the use of non-dissociative amnestic is a promising 618 avenue for first-line intervention in trauma.

\section{Acknowledgements}

This research has was funded internally via UCL.

Declaration of Interest

None.

\section{References}

Amey BD, Ballinger JA, Harrison EE (1981). Prehospital 625 administration of nitrous oxide for control of pain. Annals of 626 Emergency Medicine 10, 247-251.

APA (2013). Diagnostic and Statistical Manual of Mental 627 Disorders (DSM-5). American Psychiatric Association: Washington, D.C.

Baayen RH, Davidson DJ, Bates DM (2008). Mixed-effects modeling with crossed random effects for subjects and items. Journal of Memory and Language 59, 390-412.

Bates DM (2010). lme4: Mixed-effects modeling with R (http://lme4.r-forge.r-project.org/book).

Beck AT, Steer RA, Carbin MG (1988). Psychometric properties of the beck depression inventory: twenty-five years of evaluation. Clinical Psychology Review 8, 77-100.

Bisby JA, Brewin CR, Leitz JR, Curran HV (2009). Acute effects of alcohol on the development of intrusive memories. Psychopharmacology 204, 655-666.

Bliss TV, Collingridge GL (1993). A synaptic model of memory: long-term potentiation in the hippocampus. Nature 361, 31-39.

Bremner JD, Krystal JH, Putnam FW, Southwick SM, Marmar C, Charney DS, Mazure CM (1998). Measurement 646 of dissociative states with the clinician-administered 647 dissociative states scale (CADSS). Journal of Traumatic Stress 648 11, 125-136.

Brewin CR (2001a). A cognitive neuroscience account of 650 posttraumatic stress disorder and its treatment. Behaviour 651 Research and Therapy 39, 373-393.

Brewin CR (2001b). Memory processes in post-traumatic stress disorder. International Review of Psychiatry 13, 159-163.

Brewin CR (2013). Episodic memory, perceptual memory, and 656 their interaction: foundations for a theory of posttraumatic 657 stress disorder. Psychological Bulletin 140, 69-97. 658

Brewin CR, Dalgleish T, Joseph S (1996). A dual 659 representation theory of posttraumatic stress disorder. $\quad 660$ Psychological Review 103, 670.

Briere J, Scott C, Weathers F (2014). Peritraumatic and 661 persistent dissociation in the presumed etiology of PTSD. 663 American Journal of Psychiatry 162, 2295-2301. 
Carlson EB, Putnam FW (1993). An update on the dissociative experiences scale. Dissociation: Progress in the Dissociative Disorders 6, 16-27.

Cohen S, Kozlovsky N, Matar MA, Kaplan Z, Zohar J, Cohen H (2012). Post-exposure sleep deprivation facilitates correctly timed interactions between glucocorticoid and adrenergic systems, which attenuate traumatic stress responses. Neuropsychopharmacology 37, 2388-2404.

Das RK, Freeman TP, Kamboj SK (2013). The effects of $N$-methyl D-aspartate and B-adrenergic receptor antagonists on the reconsolidation of reward memory: a meta-analysis. Neuroscience $\mathcal{E}$ Biobehavioral Reviews 37, 240-255.

Diekelmann S, Born J (2010). The memory function of sleep. Nature Reviews Neuroscience 11, 114-126.

Dunsmoor JE, Murty VP, Davachi L, Phelps EA (2015). Emotional learning selectively and retroactively strengthens memories for related events. Nature 520, 345-348.

Ehlers A, Hackmann A, Michael T (2004). Intrusive reexperiencing in post-traumatic stress disorder: phenomenology, theory, and therapy. Memory 12, 403-415.

Emmanouil DE, Quock RM (2007). Advances in understanding the actions of nitrous oxide. Anesthesia Progress 54, 9-18.

Feder A, Parides MK, Murrough JW, Perez AM, Morgan JE, Saxena S, Kirkwood K, Aan Het Rot M, Lapidus KA, Wan L-B (2014). Efficacy of intravenous ketamine for treatment of chronic posttraumatic stress disorder: a randomized clinical trial. JAMA Psychiatry 71, 681-688.

Fisher JD, Brown SN, Cooke MW, Committee JRCAL, Association AS, Wales N, Ireland N (2006). UK Ambulance Service clinical practice guidelines. London: Joint Royal College Ambulance Liaison Committee.

Frey U, Morris RG (1997). Synaptic tagging and long-term potentiation. Nature 385, 533-536.

Gais S, Born J (2004). Declarative memory consolidation: mechanisms acting during human sleep. Learning $\mathcal{E}$ Memory 11, 679-685.

Hackmann A, Ehlers A, Speckens A, Clark D (2004). Characteristics and content of intrusive memories in PTSD and their changes with treatment. Journal of Traumatic Stress 17, 231-240.

Halligan SL, Michael T, Clark DM, Ehlers A (2003). Posttraumatic stress disorder following assault: the role of cognitive processing, trauma memory, and appraisals. Journal of Consulting and Clinical Psychology 71, 419.

Hellawell SJ, Brewin CR (2004). A comparison of flashbacks and ordinary autobiographical memories of trauma: content and language. Behaviour Research and Therapy 42, 1-12.

Holmes EA, James EL, Coode-Bate T, Deeprose C (2009). Can playing the computer game 'Tetris' reduce the build-up of flashbacks for trauma?: a proposal from cognitive science. PLoS ONE 4, e4153.

Holmes EA, James EL, Kilford EJ, Deeprose C (2010). Key steps in developing a cognitive vaccine against traumatic flashbacks: visuospatial tetris versus verbal pub quiz. PLoS ONE 5, e13706.

James EL, Bonsall MB, Hoppitt L, Tunbridge EM, Geddes JR, Milton AL, Holmes EA (2015). Computer game play reduces intrusive memories of experimental trauma via reconsolidation-update mechanisms. Psychological Science 26, 1201-1215.

Jevtović-Todorović V, Todorovć S, Mennerick S, Powell S, 726 Dikranian K, Benshoff N, Zorumski C, Olney J (1998) 727 Nitrous oxide (laughing gas) is an NMDA antagonist, $\quad 728$ neuroprotectant and neurotoxin. Nature Medicine 4, 460-463. 729

Jevtovic-Todorovic V, Wozniak DF, Benshoff ND, Olney JW 730 (2001). A comparative evaluation of the neurotoxic 731 properties of ketamine and nitrous oxide. Brain Research 732 895, 264-267.

Ji D, Wilson MA (2007). Coordinated memory replay in the 734 visual cortex and hippocampus during sleep. Nature $\quad 735$ Neuroscience 10, 100-107.

Jones M, Errington M, French P, Fine A, Bliss T, Garel S, 737 Charnay P, Bozon B, Laroche S, Davis S (2001). A 738 requirement for the immediate early gene Zif268 in the 739 expression of late LTP and long-term memories. Nature 740 Neuroscience 4, 289-296.

Lahti T, Methuen T, Roine R, Seppa KL, Sinclair D, Partinen M, Alho H (2011). The impacts of nitrous oxide gas on sleep quality during alcohol withdrawal. $B M C$ Research Notes 4, 108.

McGaugh JL (2004). The amygdala modulates the consolidation of memories of emotionally arousing experiences. Annual Review of Neuroscience 27, 1-28.

Michael T, Ehlers A, Halligan S, Clark D (2005). Unwanted memories of assault: what intrusion characteristics are 750 associated with PTSD?. Behaviour Research and Therapy 43, 751 613-628.

Murray J, Ehlers A, Mayou RA (2002). Dissociation and 753 post-traumatic stress disorder: two prospective studies of 754 road traffic accident survivors. British Journal of Psychiatry 755 180, 363-368.

O'Donnell ML, Creamer M, Pattison P (2004). Posttraumatic 757 stress disorder and depression following trauma: $\quad 758$ understanding comorbidity. American Journal of Psychiatry 759 161, 1390-1396.

O'Sullivan Í, Benger J (2003). Nitrous oxide in emergency 761 medicine. Emergency Medicine Journal 20, 214-217. 762

Payne JD, Nadel L (2004). Sleep, dreams, and memory 763 consolidation: the role of the stress hormone cortisol. $\quad 764$ Learning E Memory 11, 671-678.

Porcheret K, Holmes EA, Goodwin GM, Foster RG, Wulff K 766 (2015). Psychological effect of an analogue traumatic event 767 reduced by sleep deprivation. Sleep 38, 1017-1025. 768

Porges SW (1997). Emotion: an evolutionary by-product of 769 the neural regulation of the autonomic nervous systema. 770 Annals of the New York Academy of Sciences 807, 62-77. 771

R Core Development Team (2014). R: A Language and 772 Environment for Statistical Computing. R Foundation for 773 Statistical Computing: Vienna, Austria, 2012.

Rasch B, Büchel C, Gais S, Born J (2007). Odor cues during 775 slow-wave sleep prompt declarative memory consolidation. 776 Science 315, 1426-1429.

Roozendaal B (2000). Glucocorticoids and the regulation $\quad 778$ of memory consolidation. Psychoneuroendocrinology 25, 779 213-238.

Roozendaal B (2002). Stress and memory: opposing effects of glucocorticoids on memory consolidation and 
memory retrieval. Neurobiology of Learning and Memory 78, 578-595.

Roozendaal B, Quirarte GL, McGaugh JL (2002).

Glucocorticoids interact with the basolateral amygdala $\beta$-adrenoceptor-cAMP/cAMP/PKA system in influencing memory consolidation. European Journal of Neuroscience 15, 553-560.

Sajikumar S, Frey JU (2004). Late-associativity, synaptic tagging, and the role of dopamine during LTP and LTD. Neurobiology of Learning and Memory 82, 12-25.

Schönenberg M, Reichwald U, Domes G, Badke A, Hautzinger M (2005). Effects of peritraumatic ketamine medication on early and sustained posttraumatic stress symptoms in moderately injured accident victims. Psychopharmacology 182, 420-425.

Schönenberg M, Reichwald U, Domes G, Badke A, Hautzinger M (2008). Ketamine aggravates symptoms of acute stress disorder in a naturalistic sample of accident victims. Journal of Psychopharmacology 22, 493-497.

Shimizu E, Tang Y-P, Rampon C, Tsien JZ (2000). NMDA receptor-dependent synaptic reinforcement as a crucial process for memory consolidation. Science 290, 1170-1174.

Simons JS, Gaher RM (2005). The distress tolerance scale: development and validation of a self-report measure. Motivation and Emotion 29, 83-102.
Solomon SD, Davidson JR (1997). Trauma: prevalence, impairment, service use, and cost. Journal of Clinical Psychiatry 810 58, S5-11.

Soni M, Curran VH, Kamboj SK (2013). Identification of a narrow post-ovulatory window of vulnerability to distressing involuntary memories in healthy women. Neurobiology of Learning and Memory 104, 32-38.

Stickgold R (2005). Sleep-dependent memory consolidation. 816 Nature 437, 1272-1278.

Tarvainen M, Niskanen JP, Lipponen JA, Ranta-aho PO, 818 Karjalainen PA (2009). Kubios HRV- a software for 819 advanced heart rate variability analysis. In 4th European 820 Conference of the International Federation for Medical and 821 Biological Engineering (ed. J. Vander Sloten, P. Verdonck, 822 M. Nyssen and J. Haueisen), pp. 1022-1025. Springer: Berlin 823 Heidelberg.

Van der Kolk BA, Fisler R (1995). Dissociation and the fragmentary nature of traumatic memories: overview and exploratory study. Journal of Traumatic Stress 8, 505-525.

Van der Kolk BA, McFarlane AC, Weisaeth L (1996). Traumatic Stress. Guilford: New York.

Verwoerd J, de Jong P, Wessel I (2008). Low attentional control and the development of intrusive memories following a laboratory stressor. Journal of Psychopathology and Behavioral Assessment 30, 291-297.
812 813 814 815

9

.

